\title{
Hypoglycaemia related to inherited metabolic diseases in adults
}

\author{
Claire Douillard ${ }^{1,2^{*}}$, Karine Mention ${ }^{2}$, Dries Dobbelaere ${ }^{2}$, Jean-Louis Wemeau', Jean-Marie Saudubray ${ }^{3}$ and \\ Marie-Christine Vantyghem ${ }^{1}$
}

\begin{abstract}
In non-diabetic adult patients, hypoglycaemia may be related to drugs, critical illness, cortisol or glucagon insufficiency, non-islet cell tumour, insulinoma, or it may be surreptitious. Nevertheless, some hypoglycaemic episodes remain unexplained, and inborn errors of metabolism (IEM) should be considered, particularly in cases of multisystemic involvement. In children, IEM are considered a differential diagnosis in cases of hypoglycaemia. In adulthood, IEMrelated hypoglycaemia can persist in a previously diagnosed childhood disease. Hypoglycaemia may sometimes be a presenting sign of the IEM. Short stature, hepatomegaly, hypogonadism, dysmorphia or muscular symptoms are signs suggestive of IEM-related hypoglycaemia. In both adults and children, hypoglycaemia can be clinically classified according to its timing. Postprandial hypoglycaemia can be an indicator of either endogenous hyperinsulinism linked to non-insulinoma pancreatogenic hypoglycaemia syndrome (NIPHS, unknown incidence in adults) or very rarely, inherited fructose intolerance. Glucokinase-activating mutations (one family) are the only genetic disorder responsible for NIPH in adults that has been clearly identified so far. Exercise-induced hyperinsulinism is linked to an activating mutation of the monocarboxylate transporter 1 (one family). Fasting hypoglycaemia may be caused by IEM that were already diagnosed in childhood and persist into adulthood: glycogen storage disease (GSD) type I, III, O, VI and IX; glucose transporter 2 deficiency; fatty acid oxidation; ketogenesis disorders; and gluconeogenesis disorders. Fasting hypoglycaemia in adulthood can also be a rare presenting sign of an IEM, especially in GSD type III, fatty acid oxidation [medium-chain acyl-CoA dehydrogenase (MCAD), ketogenesis disorders (3-hydroxy-3-methyl-glutaryl-CoA (HMG-CoA) lyase deficiency, and gluconeogenesis disorders (fructose-1,6-biphosphatase deficiency)].
\end{abstract}

Keywords: Inborn errors of metabolism, Hypoglycaemia, Non-insulinoma pancreatogenic hypoglycaemia syndrome, Glycogen storage disease, Fatty acid oxidation disorder, Gluconeogenesis

\section{Introduction}

Inborn errors of metabolism (IEM) are inherited diseases, usually recessive, which have recently become an important unrecognized part of adult medicine. They are usually classified into 3 main groups: 1) intoxication diseases (i.e., amino-acidopathies, organic aciduria, fructose intolerance and galactosaemia, iron and copper overload, porphyria); 2) diseases linked to energy deficiency (i.e., glycogenolysis, mitochondrial diseases, disorders of fatty acid oxidation

\footnotetext{
* Correspondence: claire.douillard@chru-lille.fr

'Service d'Endocrinologie et maladies Métaboliques, Hôpital Claude Huriez, Centre Hospitalier Régional et Universitaire de Lille, 1, Rue Polonovski, Lille cedex 59037, France

${ }^{2}$ Centre de Référence des Erreurs Innées du Métabolisme -Hôpital Jeanne de Flandres, Centre Hospitalier Régional et Universitaire de Lille, avenue Eugène Avinée, Lille cedex 59037, France

Full list of author information is available at the end of the article
}

and ketogenesis, congenital lactic acidosis); and 3) diseases due to degradation or synthesis defect of complex molecules (i.e., lysosomal or peroxisomal diseases, and congenital disorders of glycosylation). The clinical presentations of these disorders are very diverse and can encompass any symptoms at any age in any scenario with any mode of inheritance [1]. The aim of this paper is to focus on the diagnostic approach to these metabolic disorders in adults presenting with hypoglycaemia.

The diagnosis of hypoglycaemia in adults must first be firmly established before starting a diagnostic work-up that includes numerous and costly investigations. A positive diagnosis of hypoglycaemia is made when the venous blood glucose level is $<0.55 \mathrm{~g} / \mathrm{L}$ (or $<3 \mathrm{mmol} / \mathrm{L}$ ), obtained if possible at the time of the symptoms [2].

\section{Biomed Central}


In a non-diabetic adult patient, hypoglycaemia may be related to drugs, critical illness, cortisol or glucagon insufficiency, non-islet cell tumour, insulinoma, or it may be surreptitious (Figure 1) [2]. Some hypoglycaemic episodes remain unexplained, in which case the differential diagnosis should be narrowed down to less frequent causes such as inherited metabolic diseases, especially when multisystem involvement is present.

The steps for obtaining a diagnosis do not differ from those of the usual work-up, i.e., identification of the elapsed time from the last meal, circumstances of occurrence (type of meal, catabolism, concomitant infection, and physical activity), and use of drugs (type and dose). Careful physical assessment is very important, as short stature, hepatomegaly, hypogonadism, dysmorphia or muscular symptoms may suggest IEM-related hypoglycaemia.

In children presenting with hypoglycaemia, IEM appear consistently in the differential diagnosis. In adulthood, IEM-related hypoglycaemia can persist in a previously diagnosed childhood disease. In this case, hypoglycaemic episodes are usually less severe and occur less frequently than in childhood. Although rare, hypoglycaemia may be a presenting sign of IEM, even in adulthood, and must not be overlooked.

\section{Diagnosis}

The diagnostic strategy in cases of hypoglycaemia, including those linked to an IEM without malformative syndrome, is analysed in Figure 1. Basically, true hypoglycaemia must be identified before the diagnostic work-up is started [2]. The main issue is that the clinical signs of hypoglycaemia can lack specificity, explaining why the diagnosis of "hypoglycaemia" is often wrongly made from clinical symptoms that are independent of true hypoglycaemia. A positive diagnosis of hypoglycaemia is made when the venous blood glucose level is $<0.55 \mathrm{~g} / \mathrm{L}$ (or $<3 \mathrm{mmol} / \mathrm{L}$ ), obtained if possible at the time of the symptoms. If a blood glucose level is not available, repeated capillary glucose measurements $<0.55 \mathrm{~g} / \mathrm{L}$ that are not performed by the patient himself should incite the

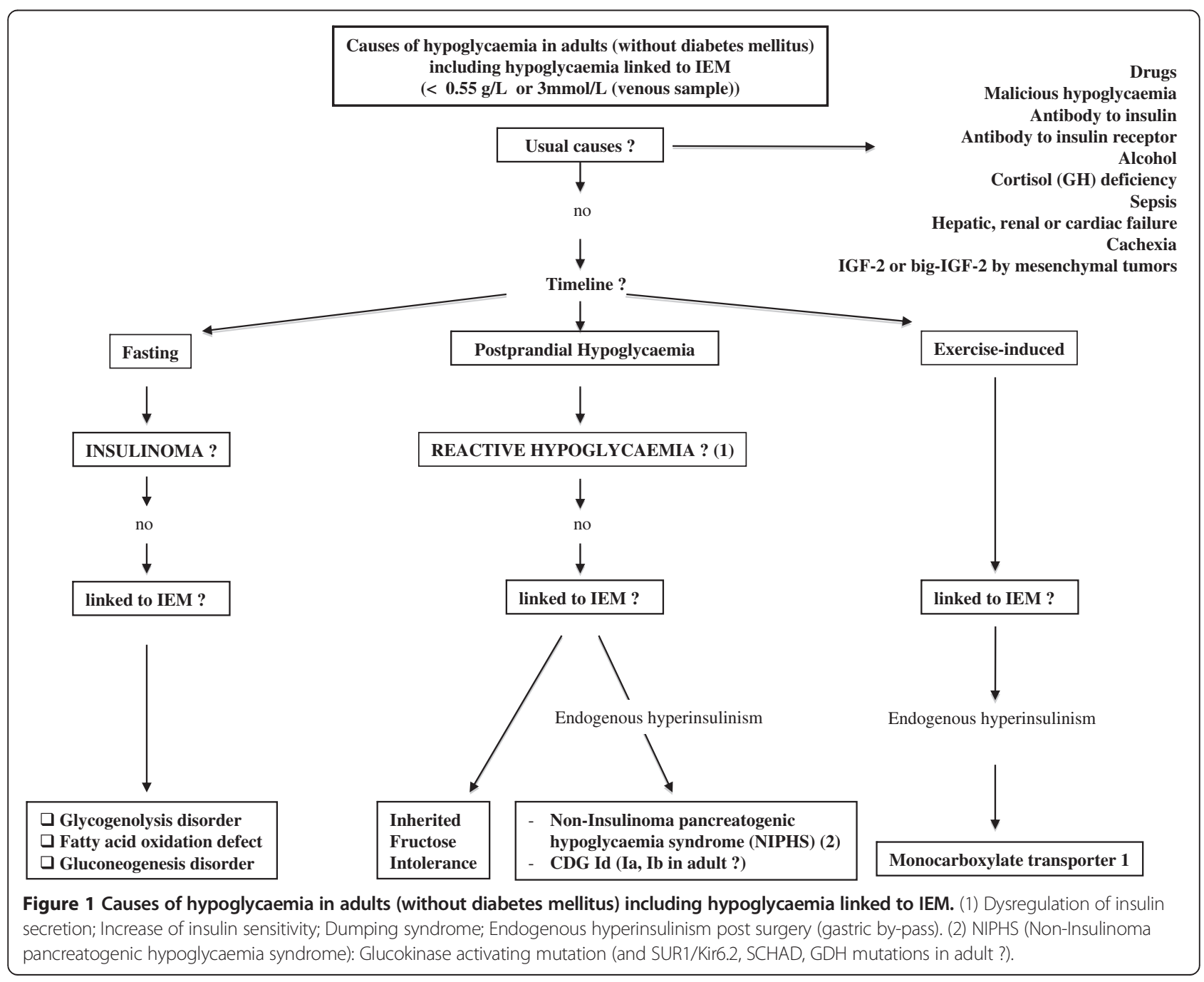


Table 1 Signs of an IEM

\begin{tabular}{lll}
\hline $\begin{array}{l}\text { When to consider a } \\
\text { glycogenolysis disorder }\end{array}$ & $\begin{array}{l}\text { When to consider a fatty acid } \\
\text { oxidation disorder }\end{array}$ & $\begin{array}{l}\text { When to consider a } \\
\text { gluconeogenesis disorder }\end{array}$ \\
\hline - Fasting hypoglycaemia & - Fasting hypoglycaemia & - Long fasting hypoglycaemia \\
- Presence of ketosis (except for GSD I) & - Absence of ketosis & - Presence of ketosis \\
- High blood lactate & - High CPK levels & - Lactic acidosis \\
- Hyperuricaemia & - Acylcarnitine accumulation & - High alanine level during fasting \\
- Hypertriglyceridaemia & (example: MCAD: high C8 and high C8/C2 ratio) & \\
- Hepatomegaly & - Urine organic acid accumulation & - Blood glycerol and urine \\
- Muscular signs & (example: HMG-COA lyase: 3-Hydroxy-3-Methylglutaric acid) & glycerol-3-phosphate accumulation during fasting \\
\hline
\end{tabular}

diagnostic work-up for hypoglycaemia. The presence of the well known Whipple's triad is therefore mandatory for starting this workup. The Whipple's triad is considered positive if biochemical hypoglycaemia (blood glucose level $<0.55 \mathrm{~g} / \mathrm{L}$ ) is accompanied by hypoglycaemic symptoms that resolve after correction of the hypoglycaemia [2].

There are several characteristic symptoms oh hypoglycaemia. First, these symptoms are varied and non-specific. Hypoglycaemia stimulates the autonomic nervous system with an adrenergic (pallor, tremor, anxiety, arterial hypertension) and cholinergic (sweat, hunger, paresthesias) reaction, which is similar to the reaction observed in anxiety. Second, neuroglycopaenic symptoms can occur and are explained by a low glucose level in the central nervous system. These symptoms are highly suggestive of a hypoglycaemia diagnosis, starting with cortical symptoms (drowsiness, confusion, visual impairment) and, if hypoglycaemia is severe, continuing to motor deficit, seizure and loss of consciousness.

In both adults and children, IEM-related hypoglycaemia can be clinically classified according to its timing as postprandial, exercise-induced or fasting hypoglycaemia. Postprandial hypoglycaemia can be an indicator of either endogenous hyperinsulinaemia linked to a non-insulinoma pancreatogenic hypoglycaemia syndrome or very rarely, inherited fructose intolerance. Exercise-induced hyperinsulinaemia is linked to an activating mutation of monocarboxylate transporter 1 transmitted as an autosomal dominant trait. Fasting hypoglycaemia may be caused by an IEM that was already diagnosed in childhood and persists into adulthood, and may sometimes even be a presenting sign of the disease. These IEM include liver glycogen storage disease, fatty acid oxidation and ketogenesis defects, and gluconeogenesis disorders. The laboratory tests usually requested by an endocrinologist and including those that are more specifically oriented toward an IEM (in italics) are :

- Plasma glucose, insulin, C-peptide

- Creatinine, liver parameters, NF, CRP, CPK, uric acid, triglycerides
- Cortisol, GH, IGF1

- Oral hypoglycaemic agents

- Blood lactate

- Free fatty acids

- 3- $\beta O H$ butyrate

- Acylcarnitines (dried blood spots)

- Plasma amino acids

- Ammonaemia

- Carnitine status (free and total)

- Urine dipstick (for ketone bodies)

- Urinary organic acids

It is of great importance that these tests be performed on blood and urine samples during the acute hypoglycaemic episode. Tables 1 and 2 show some clinical and biological features suggestive of specific IEMs.

The diagnostic work-up for hypoglycaemia is presented in the section with the same heading and describes the different causes of IEM-related hypoglycaemia.

\section{Postprandial hypoglycaemia}

Endogenous hyperinsulinaemia

Non-insulinoma pancreatogenic hypoglycaemia syndrome (NIPHS)

Postprandial hypoglycaemia is usually related to endogenous hyperinsulinaemia, or non-insulinoma pancreatogenic hypoglycaemia syndrome (NIPHS). NIPHS in adulthood was called "nesidioblastosis" in the past and is characterized, as in childhood, by an increase in the number and volume of beta cells. Three to five percent of all causes of hyperinsulinaemia are related to NIPHS diagnosed in adulthood [3-5]. Hyperinsulinaemia is a heterogeneous disorder that can be caused by various defects in the regulation of insulin secretion by the pancreatic $\beta$-cells [6]. In children these include 1) channelopathies affecting either the SUR 1 (ORPHA79643) [7] or the Kir channel (ORPHA79644) [8]; 2) enzyme defects involving glucokinase [9], glutamate dehydrogenase [10], or short-chain L3-hydroxyacyl-CoA dehydrogenase (SCHAD) [11]; and 3) defects of the monocarboxylate transporter 1 (MCT1) [12] 
Table 2 Main causes of hypoglycaemia related to inborn errors of metabolism (IEM) in adults

\begin{tabular}{llr}
\hline Diseases & $\begin{array}{l}\text { Persistent } \\
\text { hypoglycaemia }\end{array}$ & $\begin{array}{r}\text { Hypoglycaemia } \\
\text { as an indicator }\end{array}$ \\
\hline Glycogenolysis disorders & & Fasting hypoglycaemia \\
\hline
\end{tabular}

\section{Glycogenolysis disorders}

Glycogen Storage Disease

Liver:

I, VI, IX, O, Fanconi-Bickel

I, III, 0, Fanconi-Bickel

Mixed:

III, IV

Defect of fatty acid oxidation

- carnitine cycle (CPT1/2)

- CPT1

- $B$ fatty acid oxidation

- VLCAD, MCAD, SCHAD, LCHAD

- electron transfer

- ketogenesis

Gluconeogenesis

- HMG-CoA lyase

MCAD

Fructose-1,6-biphosphatase

\section{III (debranching enzyme or} amylo-1,6-glucosidase enzyme)

\section{Positive and}

molecular diagnosis

I: high blood lactates especially before meals, hypertriglyceridaemia, hyperuricaemia

Ketones rather low

III: high blood lactates especially after meals, hypertriglyceridaemia,

Ketones rather high

GSD I/III: DNA (leucocytes)

- no ketones (or rather low during hypoglycaemia)

- high free carnitine plasma level (CPT1)

- accumulation of plasma acylcarnitines (example: High C8 and high C8/C2 ratio in M(AD)

- urine organic acid accumulation

- B oxidation in vitro (lymphocytes)

- DNA (leucocytes)
Fructose-1,6-biphosphatase
- lactic acidosis

- high alanine

- ketosis

- high glycerol

- urine: high 3 Ph glycerol

Postprandial hypoglycaemia

\begin{tabular}{|c|c|c|c|}
\hline \multirow[t]{2}{*}{ NIPHS (sometimes in fasting period) } & $\begin{array}{l}\text { - hypoglycaemia during infancy } \\
\text { (SUR.1, Kir6.2, SCHAD, GDH, } \\
\text { Glucokinase }\end{array}$ & - Glucokinase mutation & - hyperinsulinism \\
\hline & $\begin{array}{l}\text { - sometimes progression } \\
\text { to diabetes in adulthood } \\
\text { (especially SUR-1) }\end{array}$ & & $\begin{array}{l}\text { - hyperammonemia (GDH) } \\
\text { - Genotyping (DNA leucocytes) }\end{array}$ \\
\hline \multirow{5}{*}{$\begin{array}{l}\text { CDG la, lb, Id } \\
\text { (sometimes at anytime) }\end{array}$} & - CDG Id & no & Isoelectric focussing of transferrin \\
\hline & & & - phosphomannomutase gene (la) \\
\hline & & & - phosphomannomutase isomerase gene (Ib) \\
\hline & & & - 1,3-mannosyltransferase (Id) \\
\hline & & & Hyperinsulinism \\
\hline \multirow[t]{3}{*}{ Inherited fructose intolerance } & $\begin{array}{l}\text { - After ingestion of fructose } \\
\text { (fruits, sucrose, sweet foods) }\end{array}$ & & - fructose test tolerance iv \\
\hline & - Late postprandial period & & - breath test fructose \\
\hline & & & - DNA leucocytes : aldolase B gene \\
\hline
\end{tabular}

\section{Exercise-induced hypoglycaemia}

yes

Genotyping (DNA leucocytes)

GSD, glycogen storage disease; CPT, carnitine palmitoyltransferase-1; VLCAD, very long-chain acyl-CoA dehydrogenase; MCAD, medium-chain acyl-CoA dehydrogenase; LCHAD, long-chain 3-hydroxyacyl-COA dehydrogenase; SCHAD, short-chain L-3-hydroxyacyl-CoA dehydrogenase; IGDH, glutamate dehydrogenase; MCT1, monocarboxylate transporter 1; CDG, congenital disorders of glycosylation; NIPHS, non-insulinoma pancreatogenic hypoglycaemia syndrome. 
and the mitochondrial uncoupling protein 2 (UCP2) [13]. These metabolic diseases disturb $\mathrm{B}$-cell intramitochondrial energy metabolism and induce non-regulated ATP overproduction, which causes abnormal inactivation of the potassium channel and stimulation of the calcium channel responsible for hyperinsulinaemia. In addition, modifications of insulin secretion implicating the insulin receptor [14] and, more recently, Hepatocyte Nuclear Factor 4 (HNF4) alpha, a transcription factor involved in maturityonset diabetes of the young (MODY), have also been described (ORPHA263455) [15]. Up till now, in endogenous hyperinsulinism, neither inactivating mutations of SUR 1, Kir channel and SCHAD (ORPHA35123) [11] nor activating mutations of glutamate dehydrogenase (GDH, Hyperinsulinism-Hyperammonaemia syndrome, ORPHA35878) $[16,17]$ have been observed in adulthood [18]. This is possibly due to an early presentation of these disorders in children, which are not seen in adulthood. However the possibility that such rare metabolic mechanisms are overlooked and are not yet familiar to adult endocrinologists cannot be excluded. Finally, glucokinase-activating mutation transmitted as an autosomal dominant trait is the only genetic disorder that has been clearly identified in adults to date $(<1-9 / 1,000,000$; ORPHA79299) [19].

From a clinical point of view, all of the causes of hyperinsulinism listed above (except monocarboxylate transporter 1, see below) actually present mainly with postprandial hypoglycaemia but can also appear in the fasting state.

\section{Congenital disorders of glycosylation (CDG)}

CDG syndromes (<1-9/100,000, ORPHA137), especially the Ia (ORPHA79318), Ib (ORPHA79319) and Id (ORPHA79321) types, can also lead to hypoglycaemia via hyperinsulinaemia [20-22]. A few cases have been reported in adults, particularly a case of CDG-Id in a patient who died at the age of 19 years from hyperinsulinaemic hypoglycaemia, with $\beta$-cell hyperplasia on the autopsy, associated with Dandy-Walker malformation, dysmorphic facial features, and marked hypotonia. A unique homozygote mutation of the ALG3 gene encoding mannosyltransferase was identified [23].

\section{Inherited fructose intolerance}

Inherited fructose intolerance (HFI or fructosaemia, $<1-9$ / 100,000; ORPHA469) is linked to a fructose-1-phosphate aldolase deficiency. In this autosomal recessive disorder, fructose ingestion (especially that contained in fruits, but also sucrose, which is found in many sweet foods) generally induces gastrointestinal disorders and postprandial hypoglycaemia. In case of misdiagnosis, it leads to hepatomegaly and proximal tubular dysfunction, sometimes with liver steatosis and kidney failure with delayed growth.
This disease may manifest in adulthood and should be considered in case of hypoglycaemia with digestive intolerance in relation to any intake of fructose, and aversion to sweet food [24]. The diagnosis was made at the age of 50 in a woman who presented a life-long history of aversion to sugary foods (nausea, vomiting, diffuse abdominal pain and hypoglycaemic symptoms, even after the smallest amount of sugar or fruit) [25]. Some other adult cases were diagnosed after the development of lifethreatening reactions from intravenous infusions containing fructose, sorbitol or invert sugar (a mixture of glucose and fructose obtained by hydrolysis of sucrose) when these intravenous solutions were still in use [26]. Because approximately half of all adults with HFI are free of dental caries, the diagnosis has also been made by dentists. Although several hundred patients with HFI have been identified since its recognition as an inborn error of metabolism in 1957, these observations indicate that affected subjects may remain undiagnosed and still have a normal life span.

Whenever HFI is suspected, fructose should be eliminated. The beneficial clinical and chemical effects of withdrawal, usually seen within days, provide the first diagnostic clue. If the nutritional history is suggestive, or if other aspects are indicative of HFI (e.g., a positive family history), the disorder should be confirmed by molecular diagnosis on DNA from peripheral leukocytes. This is a non-invasive approach and has an advantage over enzymatic measurement in liver tissue since it eliminates the complication of secondary lowered aldolase activity in a damaged liver. The three most common mutations are responsible for more than $90 \%$ of HFI cases in some European regions and for still more than $50 \%$ of cases from the more heterogeneous population in North America [http:// www.bu.edu/aldolase/HFI/hfidb/DistribTable.htm].

The long-term course is usually considered favourable despite a risk of vitamin $\mathrm{C}$ deficiency requiring supplementation [27].

\section{Exercise-induced hypoglycaemia}

Exercise-induced hypoglycaemia, also caused by hyperinsulinaemia, has been described both in childhood and adulthood and is due to failed silencing of monocarboxylate transporter 1 in pancreatic $\beta$ cells, which is coded by the SLC16A1 gene [12]. This mutation causes an overtransportation of pyruvate into cells, which in pancreatic beta cells results in an unregulated overproduction of ATP. Hypoglycaemia occurs only after physical exercise and can be triggered by an IV infusion of pyruvate. It is an autosomal dominant transmitted trait $(<1-9 / 1,000,000)$.

\section{Fasting hypoglycaemia}

In adulthood, IEM that induce fasting hypoglycaemia and that were diagnosed in childhood are usually less 
severe and less frequent, even if type I glycogen storage diseases can lead to severe hypoglycaemia in adults. Otherwise, fasting hypoglycaemia in adulthood may be a presenting sign of an IEM, although they are rare.

\section{Glycogenolysis disorders}

In childhood, glycogen storage diseases (GSD), especially the liver and mixed types, are classical causes of shortterm fasting hypoglycaemia (few hours) (See Table 2). Some of these GSD, particularly types I (annual incidence around 1/100,000, ORPHA364), III (<1-9/ 100,000, ORPHA366), 0 (<1-9/1,000,000, ORPHA2089) [28] and Fanconi-Bickel syndrome due to Glut 2 deficiency $(<1-9 / 1,000,000$, ORPHA2088) [29], can induce hypoglycaemia that persists into adulthood. Type III GSD in adulthood is the only one that has been diagnosed in a hypoglycaemia work-up; this was in a 47year-old woman presenting with a history of fasting hypoglycaemia and muscle weakness since childhood [30]. Note that GSD (for example, type I) can also be diagnosed in adulthood during the investigation for liver adenomatosis or myopathy.

\section{Defects of fatty acid oxidation (FAO)}

This common group of autosomal recessive disorders is classified into 4 sub-groups: 1) carnitine cycle anomalies; 2) long-, medium- and short-chain fatty acid ß-oxidation disorders; 3) electron transfer disturbances (type II glutaric aciduria or multiple defect in acyl-CoA dehydrogenase, ORPHA26791); and 4) anomalies of ketone body synthesis [31]. Clinical symptoms are essentially similar amongst the four groups. These disorders are found either in the neonatal period, or later during childhood, adolescence or even in adulthood, often during a concomitant disease [32]. They may sometimes have a very long asymptomatic phase, thus making the diagnosis difficult. Clinical signs vary according to age. In neonates, non-ketotic hypoglycaemia is associated with hyperammonaemia, mild metabolic acidosis, along with organic aciduria, cardiomyopathy, rhabdomyolysis, liver signs and Reye's syndrome. Myopathy is the main manifestation in adulthood, but hypoglycaemia can persist or be an indicator.

1- Defects in the carnitine cycle are characterized by non-ketotic hypoglycaemia, hyperammonaemic encephalopathy, cardiomyopathy, myopathy or liver disease, usually occurring in childhood. Blood carnitine levels are very low (except for defects in carnitine palmitoyltransferase-1), and the diagnosis can be confirmed on fibroblast cultures or on lymphocytes [33]. Carnitine transfers long-chain fatty acids into the mitochondria, making them available for $\beta$-oxidation and ketogenesis by means of enzymes and transporters such as OCTN2 carnitine transporter (involved in primary carnitine deficiency, ORPHA158), carnitine palmitoyltransferase-1 (CPT1, <1/1,000,000; ORPHA156), carnitine/acylcarnitine translocase (CACT, $<1 / 1,000,000$; ORPHA159), and carnitine palmitoyltransfe rase-2 (CPT2, <1/1,000,000; ORPHA157). In childhood, hypoglycaemia is seen in CPT1 and CPT2 deficiency and can persist into adulthood (especially CPT-1), although it is less frequent and less severe [34]. Hypoglycaemia has not been a presenting sign in any cases linked to this disorder in adulthood.

2- With regard to fatty acid ß-oxidation disorders, hypoglycaemia can be an indicator of VLCAD (very longchain acyl-coA dehydrogenase, ORPHA26793), MCAD (medium-chain acyl-coA dehydrogenase, $<1-5 / 10,000$, ORPHA42), LCHAD (long-chain 3-hydroxyacyl-coA dehydrogenase, <1/1,000,000; ORPHA5) and SCHAD (shortchain 3-hydroxyacyl-coA dehydrogenase; ORPHA35123) in childhood, which can sometimes persist into adulthood. SCHAD deficiency induces hyperinsulinemic hypoglycaemia, the mechanism of which has been recently identified [16] (see above). To our knowledge, MCAD is the only $ß$-oxidation disorder in which hypoglycaemia has led to a diagnosis in adulthood. A case of MCAD defect was reported in a 33-year old man hospitalized for headaches, vomiting, confusion, coma, respiratory alkalosis with hypoglycaemia, hyperlactacidaemia, hyperammonaemia, and ventricular tachycardia, followed by a cardiac arrest with renal insufficiency and rhabdomyolysis [35]. MCAD was diagnosed in two men (29 and 32-years-old) who had presented since childhood with mild hypoglycaemic symptoms and had a family history of MCAD [36,37]. As for other fatty acid B-oxidation disorders, some of them (VLCAD, SCHAD) can be diagnosed in adulthood, but the presenting symptoms are muscular [38-41]. Regardless of age, cardiac arrest or sudden infant death can occur and should suggest the diagnosis. In pregnant women, intrauterine growth restriction, prematurity, preeclampsia and acute liver steatosis of pregnancy or haemolytic anaemia, elevated liver enzymes and low platelet count (HELLP) -syndrome can occur in heterozygous mothers if the foetus bears a defect in the LCHAD, trifunctional protein or carnitine palmityltransferase [42-45]. The clinical presentation of homozygous patients with LCHAD includes myopathy, recurrent episodes of rhabdomyolysis, arrhythmia, cardiomyopathy and neuropathy, as well as pigmentary retinitis with possible blindness [45].

3- Electron transfer disturbances (glutaric aciduria type II or multiple acyl-CoA dehydrogenase deficiency, ORPHA26791) involve severe manifestations in the neonatal period: hypoglycaemia, acidosis, and cardiomyopathy, sometimes associated with congenital malformations (kidney, brain, facial dysmorphism). There have been no reports of partial deficiencies with hypoglycaemia manifestations in the literature in adulthood. The oldest age for 
disease onset is 14-years-old in a Chinese adolescent boy who presented with severe vomiting, followed by rapid deterioration leading to death. However, in this case, hypoglycaemia was not a presenting symptom.

4- Ketogenesis disorders [defect in 3-hydroxy-3-methylglutaryl-CoA (HMG-CoA) synthase $(<1-9 / 1,000,000$, ORPHA35701) and HMG-CoA lyase (ORPHA20) are indicated most of the time by acute fasting hypoketotic hypoglycaemia during the neonatal or sometimes infancy period. The diagnosis might however be delayed, as was the case for a 36-year-old woman who had a history of hypoglycaemia and seizures during childhood but was finally diagnosed only at the age of 36 years after a new severe aketotic hypoglycaemic episode below $3 \mathrm{mmol} / \mathrm{L}$ with neurological symptoms (seizures, leucodystrophy) [31]. The diagnosis was an HMG-CoA lyase defect (See Table 2).

The diagnosis of all these FAO disorders relies on urine organic acid and plasma acylcarnitine profiles during hypoglycaemia, and the simple quick urine dipstick test for ketone bodies is a strong indicator if negative with concomitant hypoglycaemia.

\section{Gluconeogenesis disorder}

During childhood, defects of fructose-1,6-biphosphatase $(<1-9 / 100$ 000, ORPHA348) lead to recurrent attacks of fasting hypoglycaemia and lactic acidosis triggered by fasting and catabolic circumstances. In adulthood, a defect in fructose-1,6-biphosphatase was diagnosed in a young woman who presented during the second trimester of pregnancy with recurrent hypoglycaemia and acidosis [46]. Pregnancy is possible: 3 cases have been reported in the same patient who had followed a strict diet with nocturnal enteral nutrition [45]. These pregnancies were complicated by mild gestational diabetes, increased need for uncooked cornstarch and postpartum hypoglycaemia. No complications were noted in the children. Nevertheless, the mother developed deafness and cognitive impairment afterwards.

\section{Other rare cases of hypoglycemia linked to iem but not yet described in adults}

\section{Organic aciduria}

Different types of organic aciduria can occasionally induce hypoglycaemia, especially during acute metabolic decompensation. Type II glutaric aciduria or multiple defects in acyl-CoA dehydrogenase (ORPHA26791) have already been mentioned. Severe hypoglycaemia has been reported only in a few cases, usually early in life. These defects include 3 methylcrotonyl-coenzyme A carboxylase $[47,48]$, gammahydroxybutyric aciduria, and defects in malonyl-coenzyme A decarboxylase (a rare disorder associated with metabolic acidosis, hypoglycaemia and/ or cardiomyopathy and neurological signs) [49].

\section{Biotin-responsive multiple carboxylase deficiency}

Some cases of defects in biotinidase (BRMCD: biotin responsive multiple carboxylase deficiency) are generally associated with episodes of coma, lactic acidosis with ketosis, neurological disorders and cutaneous symptoms (rashes, eczema, alopecia) in patients aged 3 months to 14 years [50,51]. A few cases have been associated with hyperglycaemia, which may suggest diabetes due to the ketoacidosis. In contrast, hypoglycaemia is sometimes present. The administration of biotin $10 \mathrm{mg} /$ day provides a dramatic and sustained improvement.

\section{Respiratory chain defects}

Respiratory chain defects can also lead to hypoglycaemia during the neonatal period or in early infancy to childhood [52].

\section{Diagnosis workup}

When true hypoglycaemia, according to the above definition and meeting the Whipple's triad criteria, is diagnosed, the usual causes (as presented in the introduction section and in Figure 1) should first be ruled out. The diagnosis workup is summarized in Figure 2.

\section{Postprandial hypoglycaemia}

Postprandial symptoms are non-specific and are usually due to an adrenergic reaction. If these symptoms are not associated with true hypoglycaemia, the term "postprandial syndrome" is preferred. If the blood glucose level is $<0.55 \mathrm{~g} / \mathrm{L}$, then the term reactive (or functional) hypoglycaemia (RH) should be used [53]. CGMS (continuous glucose monitoring system) can help to diagnose $\mathrm{RH}$. The oral glucose tolerance test is difficult to interpret, as moderate biological hypoglycaemia is frequent but is not systematically associated with clinical symptoms. $\mathrm{RH}$ can be due to:

a. insulin secretion impairment, with excessive insulin secretion in response to food intake containing carbohydrates with a high glycaemic index;

b. increased insulin sensitivity in young and slim patients [54];

c. hypoglycaemia in patients with gastrectomy with or without pyloroplasty or vagotomy, leading to dumping syndrome (abdominal pain, nausea, diarrhoea and hypoglycaemia due to excessive insulin secretion in response to an excessive intake of carbohydrates);

d. endogenous hyperinsulinism after Roux-en-Y gastric bypass for obesity, first described by GJ Service et al. [55], in which GLP-1 plays a role.

Lastly, if none of these causes can explain postprandial hypoglycaemia, then an IEM could be hypothesized. 


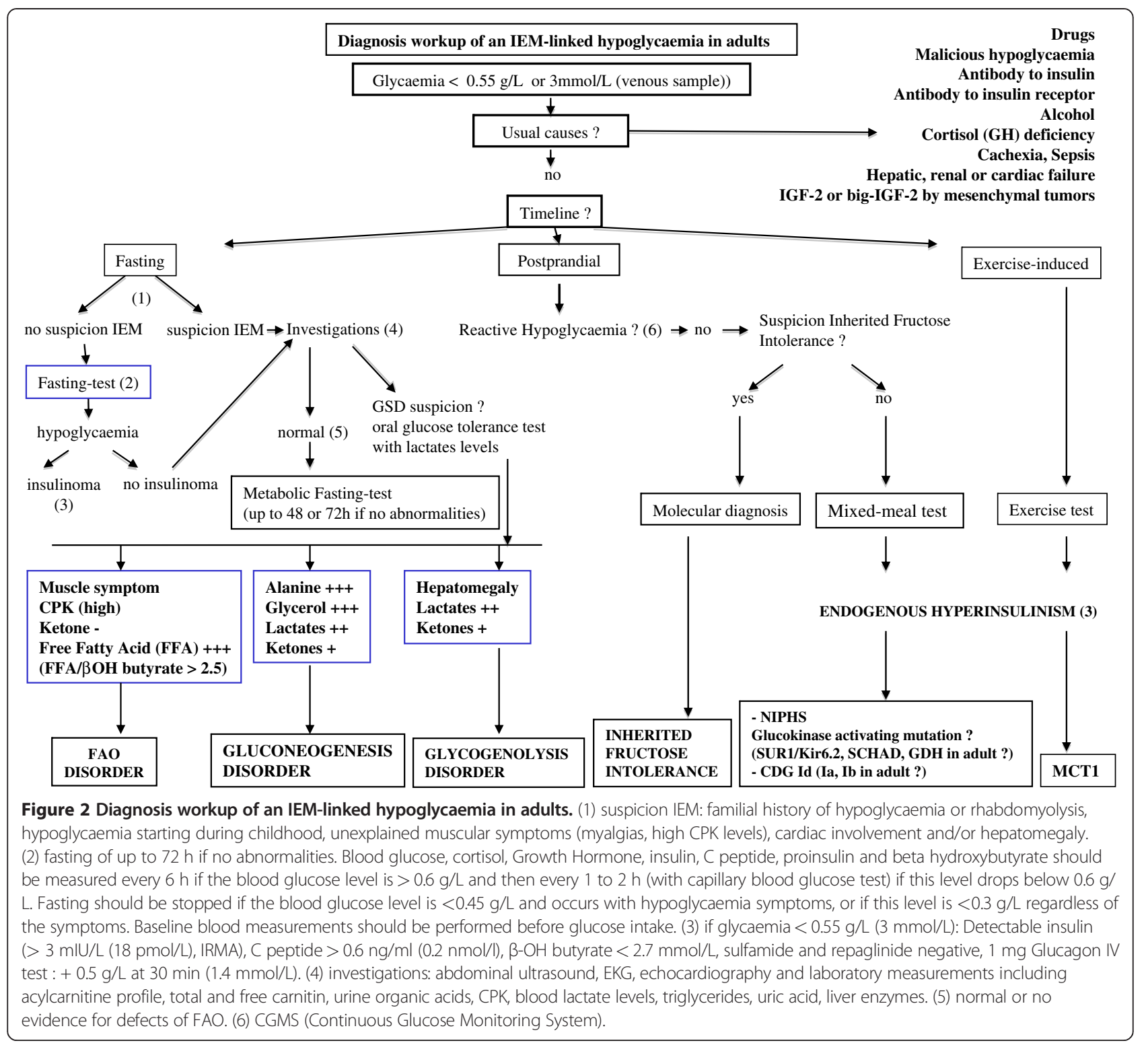

a. If the clinical context is suggestive of HFI, an assessment should be done for hepatomegaly and liver enzyme abnormalities. If the diagnosis is highly probable, and even if the liver enzymes are normal, the molecular diagnosis of HFI should be performed.

b. If the clinical context is not suggestive of HFI, then endogenous hyperinsulinism should be ruled out (Figure 2). The recent guidelines suggest that a mixed meal (recreating if possible the circumstances of hypoglycaemia) is indicated with the following measurements done at baseline and every $30 \mathrm{~min}$ for 5 h: blood glucose level, insulin, C-peptide, proinsulin, beta hydroxybutyrate, sulfamide and repaglinide. If hypoglycaemia occurs (neuroglycopaenic symptoms and blood glucose level $<0.45 \mathrm{~g} / \mathrm{L}$ ), the test should be stopped but with a last measurement taken before glucose intake. If endogenous hyperinsulinism is present, an investigation for insulinoma should be done, as there have been rare observations of insulinoma presenting with postprandial hypoglycaemia. Therefore, a CT scan, MRI, endoscopic ultrasound, octreoscan and PET scan are mandatory. If the results are negative or if there are discrepancies, a work-up for some types of mutations can be done: glucokinase activation mutation, mainly if there is a family history (autosomal dominant transmission), SUR-1 or Kir 6-2, because these mutations are frequent in children but have not yet been described in adults. If there are neurological symptoms with 
hyperammonaemia, investigations can be done for GDH mutations (though not yet described in adults) and SCHAD. Lastly, if the clinical symptoms are suggestive (malformations, facial dysmorphy, hypogonadism), type Id CDG should be ruled out.

\section{Exercise-induced hypoglycaemia}

If exercise-induced hypoglycaemia is suspected or diagnosed, an exercise test should be performed to recreate the circumstances in which symptomatic hypoglycaemia is likely to occur. If endogenous hyperinsulinism is diagnosed, an investigation for SLC16A1 (coding for monocarboxylate transporter 1) mutation should be done.

\section{Fasting hypoglycaemia}

The presence of fasting hypoglycaemia should prompt practitioners to look for a clinical context compatible with IEM: family history of hypoglycaemia or rhabdomyolisis, hypoglycaemia starting in childhood, unexplained muscular symptoms (myalgias, high CPK levels), cardiac involvement and/or hepatomegaly.

If there is no suspicion of IEM, fasting of up to $72 \mathrm{~h}$ during a hospital stay should be performed in order to rule out insulinoma (incidence of 4/1,000,000 per year). Such a fast enables $99 \%$ of hypoglycaemia cases associated with hyperinsulinism to be diagnosed. Blood glucose, cortisol, Growth Hormone, glucagon, insulin, C peptide, proinsulin and beta hydroxybutyrate should be measured every $6 \mathrm{~h}$ if the blood glucose level is $>0.6 \mathrm{~g} / \mathrm{L}$ (with capillary blood glucose test) and then every 1 to $2 \mathrm{~h}$ if this level drops below $0.6 \mathrm{~g} / \mathrm{L}$. Fasting should be stopped if the blood glucose level is $<0.45 \mathrm{~g} / \mathrm{L}$ and occurs with hypoglycaemia symptoms, or if this level is $<0.3 \mathrm{~g} / \mathrm{L}$ regardless of the symptoms. Baseline blood measurements (with sulfamide and repaglinide) should be performed before glucose intake. A diagnostic workup to localize the insulinoma should be started only if the fast reveals hyperinsulinemic hypoglycaemia $[2,56]$.

If IEM-related fasting hypoglycaemia is suspected, the following minimal investigations should be performed: a abdominal ultrasound, EKG, echocardiography and laboratory measurements including acylcarnitine profile, total and free carnitin, urine organic acids, CPK, blood lactate levels, triglycerides, uric acid, liver enzymes. Hepatomegaly associated with a high blood lactate level, as well as high triglyceride, is suggestive of glycogenosis. Oral glucose tolerance test has to be performed with measurement of lactates before and $2 \mathrm{~h}$ after the glucose intake: a decrease in lactates in the latter situation will suggest type I glycogen storage disease (GSD) whereas an increase in lactates suggests a type III GSD. In both cases, these results should prompt appropriate enzymatic and molecular laboratory investigations. Muscular manifestations associated with a high CPK, unexplained cardiomyopathy, an increase in some forms of acylcarnitine and a carnitine defect should lead to investigation for fatty acid oxidation disorders. In this case, fasting is not mandatory and could be even harmful because of the risk of cardiac arrhythmias, especially in MCAD and VLCAD.

If these minimal investigations are normal, we propose fasting but with close cardiac monitoring: if the blood glucose level is $>0.6 \mathrm{~g} / \mathrm{L}$, measurements should be done every $6 \mathrm{~h}$ of blood glucose, insulin, C peptide, proinsulin, beta hydroxybutyrate, free fatty acid, blood lactate, total $\mathrm{CO} 2$, liver enzymes, alanine and glycerol, and then every 1 to $2 \mathrm{~h}$ if this level drops below $0.6 \mathrm{~g} / \mathrm{L}$. We propose once daily measurements of CPK, triglycerides, uric acid, urine organic acids and an acylcarnitine profile. Fasting should be stopped if the blood glucose level is $<0.45 \mathrm{~g} / \mathrm{L}$ and occurs with hypoglycaemia symptoms, or if this level is $<0.3 \mathrm{~g} / \mathrm{L}$ regardless of the symptoms. Baseline blood and urine measurements should be performed before glucose intake. If hypoglycaemia does not occur and daily urine organic acid and/or lactate results are not modified, fasting can be continued up to 48 or $72 \mathrm{~h}$ with close cardiac monitoring. The orientation of the diagnosis will be based on the results of this fast (Figure 2).

\section{Conclusion}

In adult patients without diabetes mellitus, the diagnosis of hypoglycaemia usually involves classical causes, especially insulinoma. Nevertheless, some hypoglycaemic episodes remain unexplained and less frequent causes should be considered, including inborn errors of metabolism (IEM), particularly in cases of multisystemic involvement. In children, IEM are currently considered a differential diagnosis in cases of hypoglycaemia. In adulthood, IEM-related hypoglycaemia can persist in a previously diagnosed childhood disease. In this case, hypoglycaemic episodes are usually less severe and occur less frequently than in childhood. Hypoglycaemia can sometimes be an indicator of IEM and, although these situations are rare in adults, it is important not to overlook them. A complete physical assessment taking into account the frequent multisystemic involvement, and a few simple laboratory tests (including plasma ammonaemia, lactic acid, acylcarnitine profile and urine organic acid analysis) can orientate the diagnosis towards an IEM. An extensive metabolic and molecular investigation should be performed in all unexplained NIPHS syndromes.

\section{Abbreviations}

ATP: Adenosine triphosphate; BRMCD: Biotin responsive multiple carboxylase deficiency; CACT: Carnitine/acylcarnitine translocase; CDG: Congenital disorders of glycosylation; CPT1: Carnitine palmitoyltransferase-1;

CPT2: Carnitine palmitoyltransferase-2; DNA: Deoxyribose nucleic acid; FAO: Defects of fatty acid oxidation; GDH: Glutamate dehydrogenase; GH: Growth Hormone; GSD: Glycogen storage disease; HELLP: Elevated liver 
enzyme and low platelet count; HFI: Inherited fructose intolerance; HMG-CoA lyase: 3-hydroxy-3-methyl-glutaryl-CoA lyase; HMG-CoA synthase: 3-hydroxy3-methyl-glutaryl-CoA; HNF 4 alpha: Hepatocyte Nuclear Factor 4 alpha; IEM: Inborn errors of metabolism; LCHAD: Long-chain 3-hydroxyacyl-coA dehydrogenase; MCAD: Medium-chain acyl-coA dehydrogenase; MCT 1: Monocarboxylate transporter 1; MODY: Maturity-onset diabetes of the young; NIPHS: Non-insulinoma pancreatogenic hypoglycaemia syndrome; RH: Reactive Hypoglycaemia; SCHAD: L-3-hydroxyacyl-CoA dehydrogenase; SUR 1: Sulfonylurea receptor 1; UCP2: Mitochondrial uncoupling protein 2; VLCAD: Very long-chain acyl-coA dehydrogenase.

\section{Competing interests}

The authors declare that they have no competing interests.

\section{Authors' contributions}

CD, MCV and JMS wrote and coordinated the writing of the manuscript; KM, DD and JLW participated in the design of the review and helped to draft the manuscript. All the authors read and approved the final manuscript.

\section{Author details \\ 'Service d'Endocrinologie et maladies Métaboliques, Hôpital Claude Huriez, Centre Hospitalier Régional et Universitaire de Lille, 1, Rue Polonovski, Lille cedex 59037, France. ${ }^{2}$ Centre de Référence des Erreurs Innées du Métabolisme -Hôpital Jeanne de Flandres, Centre Hospitalier Régional et Universitaire de Lille, avenue Eugène Avinée, Lille cedex 59037, France. ${ }^{3}$ Departement des maladies métaboliques, Fédération des maladies du système nerveux, Hôpital Pitié-Salpêtrière, 47-83 Boulevard de l'Hôpital, 75651, Paris cedex 13, France.}

Received: 15 October 2011 Accepted: 19 March 2012

Published: 15 May 2012

\section{References}

1. Saudubray JM, Sedel F, Walter J: Clinical approach to treatable inborn metabolic diseases. J Inherit Metab Dis 2006, 29:261-274

2. Cryer PE, Axelrod L, Grossman AB, Heller SR, Montori VM, Seaquist ER: Evaluation and management of adult hypoglycemic disorders: an Endocrine Society Clinical Practice Guideline. J Clin Endocrinol Metab 2009, 94:709-728.

3. Klöppel G, Anlauf M, Raffel A, Perren A, Knoefel WT: Adult diffuse nesidioblastosis: genetically or environmentally induced? Hum Pathol 2008, 39:3-8.

4. Raffel A, Krausch MM, Anlauf M, Wieben D, Braunstein S, Klöppel G, Röher $H D$, Knoefel WT: Diffuse nesidioblastosis as a cause of hyperinsulinemic hypoglycemia in adults: a diagnostic and therapeutic challenge. Surgery 2007, 141:179-184

5. Anlauf M, Bauersfeld J, Raffel A, Koch CA, Henopp T, Alkatout I, Schmitt A, Weber A, Kruse ML, Braunstein S, Kaserer K, Brauckhoff M, Dralle H, Moch H, Heitz PU, Komminoth P, Knoefel WT, Perren A, Klöppel G: Insulinomatosis: a multicentric insulinoma disease that frequently causes early recurrent hyperinsulinemic hypoglycemia. Am J Surg Pathol 2009, 33:339-346.

6. Dunne MJ, Cosgrove KE, Shepherd RM, Aynsley-Green A, Lindley KJ: Hyperinsulinism in infancy: from basic science to clinical disease. Physiol Rev 2004, 84:239-275.

7. Thomas PM, Cote GJ, Wohllk N, Haddad B, Mathew PM, Rabl W, AguilarBryan L, Gagel RF, Bryan J: Mutations in the sulfonylurea receptor gene in familial persistent hyperinsulinemic hypoglycemia of infancy. Science 1995, 268:426-429.

8. Thomas $P, Y e Y$, Lightner E: Mutation of the pancreatic islet inward rectifier Kir6.2 also leads to familial persistent hyperinsulinemic hypoglycemia of infancy. Hum Mol Genet 1996, 5:1809-1812.

9. Glaser B, Kesavan P, Heyman M, Davis E, Cuesta A, Buchs A, Stanley CA, Thornton PS, Permutt MA, Matschinsky FM, Herold KC: Familial hyperinsulinism caused by an activating glucokinase mutation. N Engl J Med 1998, 338:226-230.

10. Stanley CA, Lieu Y, Hsu B, Burlina AB, Greenberg CR, Hopwood NJ, Perlman $\mathrm{K}$, Rich BH, Zammarchi E, Poncz M: Hyperinsulinemia and hyperammonemia in infants with regulatory mutations of the glutamate dehydrogenase gene. N Engl J Med 1998, 338:1352-1357.

11. Clayton PT, Eaton S, Aynsley-Green A, Edginton M, Hussain K, Krywawych S, Datta V, Malingre HE, Berger R, van den Berg IE: Hyperinsulinism in short-chain
L-3-hydroxyacyl-CoA dehydrogenase deficiency reveals the importance of beta-oxidation in insulin secretion. J Clin Invest 2001, 108:457-465.

12. Otonkoski T, Jiao H, Kaminen-Ahola N, Tapia-Paez I, Ullah MS, Parton LE, Schuit F, Quintens R, Sipilä I, Mayatepek E, Meissner T, Halestrap AP, Rutter GA, Kere J: Physical exercise-induced hypoglycemia caused by failed silencing of monocarboxylate transporter 1 in pancreatic beta cells. Am J Hum Genet 2007, 81:467-474.

13. Gonzalez-Barroso MM, Giurgea I, Bouillaud F, Anedda A, Bellanné-Chantelot $C$, Hubert $L$, de Keyzer $Y$, de Lonlay P, Ricquier D: Mutations in UCP2 in congenital hyperinsulinism reveal a role for regulation of insulin secretion. PLOS One 2008, 3:e3850.

14. Hojlund $K$, Hansen T, Lajer M, Henriksen JE, Levin K, Lindholm J, Pedersen O, Beck-Nielsen $\mathrm{H}$ : A novel syndrome of autosomal-dominant hyperinsulinemic hypoglycemia linked to a mutation in the human insulin receptor gene. Diabetes 2004, 53:1592-1598.

15. Pearson E, Boj S, Steele A, Barrett T, Stals K, Shield JP, Ellard S, Ferrer J, Hattersley AT: Macrosomia and hyperinsulinaemic hypoglycaemia in patients with heterozygous mutations in the HNF4A gene. Diabetologia 2007, 50:2600-2601.

16. Li C, Chen P, Palladino A, Narayan S, Russell LK, Sayed S, Xiong G, Chen J, Stokes D, Butt YM, Jones PM, Collins HW, Cohen NA, Cohen AS, Nissim I, Smith TJ, Strauss AW, Matschinsky FM, Bennett MJ, Stanley CA: Mechanism of hyperinsulinism in short- chain 3-hydroxyacyl-CoA dehydrogenase deficiency involves activation of glutamate dehydrogenase. $J$ Biol Chem 2010, 285:31806-31818.

17. Kapoor RR, Flanagan SE, Fulton P, Chakrapani A, Chadefaux B, Ben-Omran T, Banerjee I, Shield JP, Ellard S, Hussain K: Hyperinsulinism-hyperammonaemia syndrome: novel mutations in the GLUD1 gene and genotype-phenotype correlations. Eur J Endocrinol 2009, 161:731-735.

18. Service FJ, Natt N, Thompson GB, Grant CS, van Heerden JA, Andrews JC, Lorenz E, Terzic A, Lloyd RV: Noninsulinoma pancreatogenous hypoglycemia: a novel syndrome of hyperinsulinemic hypoglycemia in adults independent of mutations in Kir6.2 and SUR1 genes. J Clin Endocrinol Metab 1999, 84:1582-1589.

19. Christesen HB, Brusgaard K, Beck Nielsen H, Brock Jacobsen B: Non-insulinoma persistent hyperinsulinaemic hypoglycaemia caused by an activating glucokinase mutation: hypoglycaemia unawareness and attacks. Clin Endocrinol (Oxf) 2008, 68:747-755.

20. Krasnewich D, O'Brien K, Sparks S: Clinical features in adults with congenital disorders of glycosylation type la (CDG-la). Am J Med Genet C Semin Med Genet 2007, 15(145C):302-306.

21. Penel-Capelle D, Dobbelaere D, Jaeken J, Klein A, Cartigny M, Weill J: Congenital disorder of glycosylation lb (CDG-lb) without gastrointestinal symptoms. J Inherit Metab Dis 2003, 26:83-85.

22. Kranz C, Sun L, Eklund EA, Krasnewich D, Casey JR, Freeze HH: CDG-Id in two siblings with partially different phenotypes. Am J Med Genet 2007, A143A:1414-1420

23. Sun L, Eklund EA, Chung WK, Wang C, Cohen J, Freeze HH: Congenital disorder of glycosylation id presenting with hyperinsulinemic hypoglycemia and islet cell hyperplasia. J Clin Endocrinol Metab 2005, 90:4371-4375.

24. Mock DM, Perman JA, Thaler M, Morris RC Jr: Chronic fructose intoxication after infancy in children with hereditary fructose intolerance. A cause of growth retardation. N Engl J Med 1983, 309:764-770

25. Yasawy MI, Folsch UR, Schmidt WE, Schwend M: Adult hereditary fructose intolerance. World J Gastroenterol 2009, 15:2412-2413.

26. Lameire N, Mussche M, Baele G, Kint J, Ringoir S: Hereditary fructose intolerance: a difficult diagnosis in the adult. Am J Med 1978, 65:416-423.

27. Guery MJ, Douillard C, Marcelli-Tourvieille S, Dobbelaere D, Wemeau JL, Vantyghem MC: Doctor, my son is so tired... about a case of hereditary fructose intolerance. Ann Endocrinol (Paris) 2007, 68:456-459.

28. Weinstein DA, Correia CE, Saunders AC, Wolfsdorf Jl: Hepatic glycogen synthase deficiency: an infrequently recognized cause of ketotic hypoglycemia. Mol Genet Metab 2006, 87:284-288.

29. Santer R, Schneppenheim R, Suter D, Schaub J, Steinmann B: Fanconi-Bickel syndrome-the original patient and his natural history, historical steps leading to the primary defect, and a review of the literature. Eur J Pediatr 1998, 157:783-797.

30. Schoser B, Gläser D, Müller-Höcker J: Clinicopathological analysis of the homozygous p.W1327X AGL mutation in glycogen storage disease type 3 . Am J Med Genet 2008, A146A:2911-2915. 
31. Bischof F, Nägele T, Wanders RJ, Trefz FK, Melms A: 3-hydroxy-3methylglutaryl-CoA lyase deficiency in an adult with leukoencephalopathy. Ann Neurol 2004, 56:727-730.

32. Saudubray JM, Martin D, de Lonlay P, Touati G, Poggi-Travert F, Bonnet D, Jouvet P, Boutron M, Slama A, Vianey-Saban C, Bonnefont JP, Rabier D, Kamoun $\mathrm{P}$, Brivet M: Recognition and management of fatty acid oxidation defects: a series of 107 patients. J Inherit Metab Dis 1999, 22:488-502.

33. Dessein AF, Fontaine M, Dobbelaere D, Mention-Mulliez K, Martin-Ponthieu A, Briand G, Vamecq J: Deuterated palmitate-driven acylcarnitine formation by whole-blood samples for a rapid diagnostic exploration of mitochondrial fatty acid oxidation disorders. Clin Chim Acta 2009, 406:23-26.

34. Bonnefont JP, Demaugre F, Prip-Buus C, Saudubray JM, Brivet M, Abadi N, Thuillier L: Carnitine palmitoyltransferase deficiencies. Mol Genet Metab 1999, 68:424-440.

35. Feillet F, Steinmann G, Vianey-Saban C, de Chillou C, Sadoul N, Lefebvre E, Vidailhet M, Bollaert PE: Adult presentation of MCAD deficiency revealed by coma and severe arrythmias. Intensive Care Med 2003, 29:1594-1597.

36. Bodman M, Smith D, Nyhan WL, Naviaux RK: Medium-chain acyl coenzyme A dehydrogenase deficiency: occurrence in an infant and his father. Arch Neurol 2001, 58:811-814

37. Heptinstall LE, Till J, Wraith JE, Besley GT: Common MCAD mutation in a healthy parent of two affected siblings. J Inherit Metab Dis 1995, 18:638-639.

38. Tong MK, Lam CS, Mak TW, Fu MY, Ng SH, Wanders RJ, Tang NL: Very long-chain acyl-CoA dehydrogenase deficiency presenting as acute hypercapnic respiratory failure. Eur Respir J 2006, 28:447-450.

39. Engbers HM, Dorland L, de Sain MG, Eskes PF, Visser G: Rhabdomyolysis in early-onset very long-chain acyl-CoA dehydrogenase deficiency despite normal glucose after fasting. J Inherit Metab Dis 2005, 28:1151-1152.

40. Shchelochkov O, Wong LJ, Shaibani A, Shinawi M: Atypical presentation of VLCAD deficiency associated with a novel ACADVL splicing mutation. Muscle Nerve 2009, 39:374-382

41. Feillet F, Ogier H, Cheillan D, Aquaviva C, Labarthe F, Baruteau J, Chabrol B, de Lonlay P, Valayanopoulos V, Garnotel R, Dobbelaere D, Briand G, Jeannesson E, Vassault A, Vianey-Saban C: Medium-chain acyl-CoAdehydrogenase (MCAD) deficiency: French consensus for neonatal screening, diagnosis, and management. Arch Pediatr 2012, 19(2):184-193.

42. Ibdah JA, Bennett MJ, Rinaldo P, Zhao Y, Gibson B, Sims HF, Strauss AW: A fetal fatty-acid oxidation disorder as a cause of liver disease in pregnant women. N Engl J Med 1999, 340:1723-1731.

43. Yang Z, Yamada J, Zhao Y, Strauss AW, Ibdah JA: Prospective screening for pediatric mitochondrial trifunctional protein defects in pregnancies complicated by liver disease. JAMA 2002, 288:2163-2166.

44. Shekhawat PS, Matern D, Strauss AW: Fetal fatty acid oxidation disorders, their effect on maternal health and neonatal outcome: impact of expanded newborn screening on their diagnosis and management. Pediatr Res 2005, 57:78R-86R.

45. Rakheja D, Bennett MJ, Rogers BB: Long-chain L-3-hydroxyacyl-coenzyme a dehydrogenase deficiency: a molecular and biochemical review. Lab Invest 2002, 82:815-824.

46. Krishnamurthy V, Eschrich K, Boney A, Sullivan J, McDonald M, Kishnani PS, Koeberl DD: Three successful pregnancies through dietary management of fructose-1,6-bisphosphatase deficiency. J Inherit Metab Dis 2007, 30:819.

47. Oude Luttikhuis HG, Touati G, Rabier D, Williams M, Jakobs C, Saudubray JM: Severe hypoglycaemia in isolated 3-methylcrotonyl-CoA carboxylase deficiency; a rare, severe clinical presentation. J Inherit Metab Dis 2005, 28:1136-1138.

48. Robbins KA, León-Ruiz EN: Anesthetic management of a patient with 3methylcrotonyl-CoA carboxylase deficiency. Anesth Analg 2008, 107:648-650.

49. de Wit MC, de Coo IF, Verbeek E, Schot R, Schoonderwoerd GC, Duran M, de Klerk JB, Huijmans JG, Lequin MH, Verheijen FW, Mancini GM: Brain abnormalities in a case of malonyl-CoA decarboxylase deficiency. Mol Genet Metab 2003, 87:102-106.

50. Yang $Y L$, Yamaguchi $S$, Tagami $Y$, Zhang $Y H$, Xiong $H$, Hasegawa $Y$, Kimura M, Hanai J, Fujita K, Qian N, He XJ, Wu Y, Bao XH, Qin J, Wu X: Diagnosis and treatment of biotinidase deficiency-clinical study of six patients. Zhonghua Er Ke Za Zhi 2003, 41:249-251.

51. Hou JW: Biotin responsive multiple carboxylase deficiency presenting as diabetic ketoacidosis. Chang Gung Med J 2004, 27(2):129-133.

52. Mochel F, Slama A, Touati G, Desguerre I, Giurgea I, Rabier D, Brivet M, Rustin P, Saudubray JM, DeLonlay P: Respiratory chain defects may present only with hypoglycemia. J Clin Endocrinol Metab 2005, 90:3780-3785.
53. Brun JF, Fedou C, Mercier J: Postprandial reactive hypoglycemia. Diabetes Metab 2000, 26:337-351

54. Tamburrano G, Leonetti F, Sbraccia P, et al: Increased insulin sensitivity in patients with idiopathic reactive hypoglycaemia. J Clin Endocrinol Metab 1989, 69:885-890.

55. Service GJ, Thompson GB, Service FJ, et al: Hyperinsulinemic hypoglycemia with nesidioblastosis after gastric-bypass surgery. N Engl J Med 2005, 353:249-254.

56. Cazabat L, Chanson P: Hypoglycemia and insulinoma. Ann Endocrinol 2009, 70:S2-S11.

doi:10.1186/1750-1172-7-26

Cite this article as: Douillard et al:: Hypoglycaemia related to inherited metabolic diseases in adults. Orphanet Journal of Rare Diseases 2012 7:26.

\section{Submit your next manuscript to BioMed Central and take full advantage of:}

- Convenient online submission

- Thorough peer review

- No space constraints or color figure charges

- Immediate publication on acceptance

- Inclusion in PubMed, CAS, Scopus and Google Scholar

- Research which is freely available for redistribution

Submit your manuscript at www.biomedcentral.com/submit
C) Biomed Central 